\title{
Uma análise sociolinguística sobre a concordância verbal de terceira pessoa do plural e o contato linguístico no Português L2 da variedade moçambicana
}

\author{
Karen Cristina da Silva Pissurno (UFRJ)* \\ https://orcid.org/0000-0002-7657-062X
}

\section{Resumo:}

Seguindo os pressupostos da Teoria da Variação e Mudança (WEINREICH; LABOV; HERZOG, 1968), objetivou-se verificar o comportamento dos moçambicanos, falantes de português como segunda língua, em relação a alternância das marcas de plural, e, assim, constatar se, em relação ao fenômeno, trata-se de uma regra variável, semicategórica ou categórica, consoante Labov (2003). Além disso, observou-se a atuação do contato linguístico com as línguas Bantu faladas no país em relação à outras variáveis linguísticas, como a escolaridade e o conhecimento de português propriamente dito, sobre os dados obtidos. Para realizar o tratamento estatístico, após recolhidas as ocorrências com e sem marcas de plural das entrevistas investigadas, utilizou-se o pacote de programas Goldvarb X. Por meio do controle estatísticos de condicionamentos (extra)linguísticos, as variáveis que se mostraram relevantes para amostra foram a escolaridade, a(s) língua(s) dominada(s) pelo informante, a transitividade verbal e a animacidade do sujeito. Notouse também que os grupos de fatores sociais podem influenciar o grau de realização das marcas e que os dados de não marcação são de naturezas distintas daqueles contextos tidos como universais para o cancelamento das marcas de número. A partir das discussões levantadas, identificou-se que o Português de Moçambique ainda seria uma variedade em formação.

Palavras-chave: Concordância Verbal. Multilinguismo. Português L2.

\section{Abstract:}

\section{A sociolinguistic analysis on third-person plural verbal agreement and linguistic contact in the $\mathbf{L 2}$ Portuguese of the Mozambican variety.}

Following the assumptions of the Theory of Variation and Change (WEINREICH; LABOV; HERZOG, 1968), the objective was to verify the behavior of

* Doutoranda em Letras Vernáculas pela Universidade Federal do Rio Janeiro.

E-mail: karenchrisufrj@gmail.com; 
Mozambicans, who speak Portuguese as a second language, in relation to the alternation of plural marks, and, thus, observe, in relation to the phenomenon, if it is a variable, semi-categorical or categorical rule, according to Labov (2003). Besides, we verified the role of linguistic contact with the Bantu languages in relation to other linguistic variables, such as education and knowledge of Portuguese, on the data obtained. To carry out the statistical treatment, after collecting the occurrences with and without plural marks from the interviews investigated, the Goldvarb X program package was used. Through the statistical control of (extra)linguistic conditions, the variables that are relevant for the sample were schooling, the language(s) dominated by the informant, verbal transitivity and the subject's animacity. It was also noted that the groups of social factors can influence the degree of marks realization and that the non-marking data are of a different nature from those contexts considered as universal for the number marks cancellation. From the discussions raised, it was identified that Portuguese from Mozambique would still be a variety in formation.

Keywords: Verbal Agreement. Multilingualism. Portuguese as a second language.

\section{Introdução}

A investigação sobre os padrões de concordância verbal de terceira pessoa, considerando dados orais contemporâneos, no Português de Moçambique teve como motivação, em primeiro lugar, a importância de descrever as variedades de Língua Portuguesa, especialmente as africanas, que possuem poucos estudos quantitativos acerca do fenômeno. Além disso, é relevante discutir a possível atuação do contato multilinguístico, fortemente presente no país, por conta das mais de 20 línguas Bantu ${ }^{1}$ (SITOE; NGUNGA, 2000) que são faladas por toda a região, na formação da variedade moçambicana do Português.

Em relação aos idiomas falados no país, pode-se destacar as seguintes línguas: $\mathrm{Ci}$ balke, Cicopi, Cindau, Cimanyica, Cinyanja,

1 Bantu refere-se a uma língua que deu origens a várias outras, bastante similares, formando um tronco linguístico. No continente africano, essa "família" de idiomas é a maior representante das línguas maternas dos indivíduos nascidos e criados nos países do centro e do sul da África. (cf. SITOE; NGUNGA, 2000)
Cinyungwe, Cisena, Citshwa, Ciute, Ciyaawo, Echuwabo, Ekoti, Elomwe, Emakhuwa, Gitonga, Kimwani, Shimakonde, Tewe, XiChangana e XiRhonga ${ }^{2}$. Além disso, também são faladas mais algumas línguas, como o francês, o inglês, o alemão, o swahili, o zulu, entre outras. Em cada província do país há a predominância de uma (ou mais) dessas línguas, todas convivendo com diferentes níveis de conhecimento da Língua Portuguesa, idioma oficial desde 1975. Em Maputo, especificamente, as línguas mais faladas são XiChangana (62\%) e XiRhonga (24\%), segundo os dados do INE (2017), mas sendo capital da cidade, recebe pessoas advindas

2 É importante salientar, a respeito do nome das línguas, que, em primeiro lugar, não há uma única ortografia, havendo possibilidades de escrever seus nomes na forma original ou na forma já aportuguesada. Em segundo lugar, alerta-se que esses idiomas fazem parte de uma família de línguas e, assim, às vezes um ou outro dialeto é destacado na literatura sobre o assunto, mas podem estar referindo-se ao mesmo subgrupo linguístico. 
de todas as províncias e, assim, pode-se supor que a diversidade de idiomas e de possíveis influências sobre Português é bastante vasta nessa sociedade.

Assim, dando continuidade ao trabalho de mestrado realizado em 2017, que considerou falantes de Português língua materna e segunda língua, e tomando por base essas motivações, optou-se, no presente artigo, por verificar apenas o comportamento dos falantes de Português como segunda língua em relação à marcação de plural nos verbos de $3^{\text {a }}$ pessoa do plural, com a pretensão de responder aos seguintes questionamentos: (i) qual é a influência do Português como L2 sobre os resultados alcançados?; (ii) quais variáveis se mostram influentes no cancelamento das marcas de número?; (iii) o Português de Moçambique já pode ser considerado uma variedade nativizada ou ainda é uma variedade em formação? A partir dessas perguntas, traçaram-se, para cada uma delas, as hipóteses e os objetivos que constituem o trabalho e são articulados a seguir.

Com relação à influência do Português como L2 sobre os resultados, supõe-se que serão encontradas estruturas na fala desses indivíduos que não são verificadas quand o o Português é a língua materna do informante. Objetiva-se, portanto, descrever os dados de fala desse perfil de entrevistados, de forma a possibilitar o debate sobre as possíveis influências das línguas autóctones faladas por eles, sobre as estruturas produzidas em Língua Portuguesa.

Quanto às variáveis relevantes, acredita-se que os fatores sociais apresentarão comportamento mais relevante do que os linguísticos nessa amostra, devido às particularidades da sociedade em questão e da relação estabelecida entre o uso das diferentes línguas envolvidas no processo. Dessa forma, o intuito será o de identificar as características sociais e linguísticas que facilitam a presença de verbos sem marcas verbais de pluralidade.

Por fim, no que se refere à classificação de uma variedade nativizada ou ainda em formação, presume-se que os dados encontrados se comportarão de maneira instável, ora se assemelhando ao comportamento da variedade europeia, ora da variedade brasileira, ora demonstrando características próprias, o que, por hipótese, revelaria um quadro de variedade em formação. Planejase, portanto, apontar a localização do Português de Moçambique em um continuum de variedades de Português, quanto aos padrões de concordância verbal.

Desse modo, o presente texto está organizado da seguinte maneira: após a introdução, descrevem-se, brevemente, as tendências encontradas nas variedades de Língua Portuguesa em relação ao fenômeno da concordância (Seção 2); relatam-se os aspectos téorico-metodológicos variacionistas adotados na investigação (Seção 3); expõem-se os resultados obtidos na análise e uma discussão qualitativa acerca dos mesmos (Seção 4); e, por fim, tecem-se as considerações finais.

\section{0 fenômeno nas variedades do português}

Diversos estudos sociolinguísticos já investigaram o comportamento da concordância verbal de terceira pessoa nas variedades de Português (brasileira - PB, europeia - PE, são-tomense - PST e moçambicana - PM), verificando que, no uso real da língua, as regras postuladas pelas gramáticas tradicionais não são categoricamente seguidas. Em outras palavras, a depender de certos contextos, sociais e linguísticos, nem sempre o verbo concorda em número com o seu su- 
jeito. Dessa forma, em algumas variedades, como as brasileiras populares, essa oscilação é maior, já em outras, como a europeia, ela ocorre em situações mais específicas.

Considerando, então, primeiramente, o Português Europeu, destaca-se que algumas pesquisas variacionistas (VAREJÃO, 2006; MONGUILHOTT, 2009; GANDRA, 2009; VIEIRA, 2011; RUBIO, 2012; MONTE, 2012; VIEIRA; BAZENGA, 2013) demonstraram haver casos de oscilação na marcação de número da variedade, mas revelando, majoritariamente, índices acima dos 95\% de aplicação da regra, o que indica o comportamento de uma regra semicategórica, de acordo com Labov (2003). Por outro lado, nos estudos em que foi registrada uma suposta variação, na ordem de 90 a $94 \%$ de preferência pelas marcas, verificou-se que a ausência de pluralidade estaria relacionada a contextos linguísticos específicos: quando o sujeito está posposto ao verbo, quando o traço semântico do sujeito é inanimado, e quando os verbos são inacusativos. Levando em conta essas especificidades, Vieira e Brandão (2014) argumentam que esses resultados não apontariam para uma regra efetivamente variável na variedade europeia, por conta do caráter universal dos contextos em que a ausência de marcas ocorre.

[...] os dados de não marcação de pluralidade dessas variedades europeias limitam-se a contextos qualitativos específicos. [...] Nas raríssimas ocorrências sem marca de número nas amostras de Oeiras e Cacém, verificam-se sobretudo contextos marcados, em que estão presentes estruturas que universalmente favoreceriam a não realização da marca: verbos cuja diferenciação entre singular e plural são de menor saliência fônica; sujeito posposto; presença do relativo "que"; sujeito inanimado e verbos intransitivos, inacusativos ou copulativos. (VIEIRA; BRANDÃO, 2014, p. 94)
No que se refere à variedade brasileira, os índices de concordância constatados pelos estudos realizados (cf., entre outros, NARO, 1981; GRACIOSA, 1991; SCHERRE; NARO, 2006; VIEIRA, 1995; VIEIRA; BAZENGA, 2013), oscilam bastante, indicando comportamento de uma regra variável, consoante Labov (2003). Assim, enquanto há trabalhos que registram alta preferência pelas marcas de número, como o de Graciosa (1991) que, ao observar o português urbano culto, encontrou 94\% de aplicação das marcas, há também aqueles que registram níveis baixíssimos, como a pesquisa de Lucchesi et al. (2009) sobre o português popular rural de Helvécia-BA, que identificou apenas $16 \%$ de marcação de plural. Percebe-se, dessa maneira, um continnum crescente de uso da concordância, a depender da escolaridade (menos x mais anos de estudo) e da localidade dos falantes envolvidos (rural x urbano), no PB.

Já os poucos trabalhos realizados sobre a variedade são-tomense (FIGUEIREDO, 2009, 2010; JON-AND, 2011; VIEIRA, 2011; BRANDÃO; VIEIRA, 2012a, 2012b), por sua vez, evidenciam uma tendência de aplicação parcial das marcas de número. Nessa realidade, observam-se índices de uma regra variável, ainda que não tão baixos e que as estruturas nas quais a ausência de plural é verificada não sejam tão variadas quanto as encontradas na variedade brasileira.

Finalmente, a variedade moçambicana dispõe de algumas investigações qualitativas (cf. GONÇALVES, 1997; GONÇALVES et al. 1998; ANTÓNIO, 2011; BAVO, 2011; NHONGO, 2005; JEQUE, 1996; JUSTINO 2015; MORENO; TUZINE, 1997), que apresentam tendências semelhantes às verificadas no PB. Resumidamente, pode-se destacar o conteúdo básico de tais estudos: 
Gonçalves (1997; 1998) apresenta a caracterização da "Tipologia de erros do Português Oral de Maputo", considerando aspectos de léxico, léxico-sintaxe, sintaxe e morfossintaxe em dados de fala, com o objetivo de construir um corpus da modalidade oral do Português de Moçambique, que servisse de fonte para estudos sobre a variedade. A autora considera apenas falantes de Português L2 e categoriza suas falas quanto ao seguimento ou afastamento das normas do PE. Nhongo (2005) realizou a primeira pesquisa sobre "desvios" à norma de concordância verbal em textos escritos por universitários. A pesquisadora mostra que quanto mais anos de escolaridade o indivíduo tiver, menos desvios ele cometerá. 0 trabalho de Justino (2015) revela contextos semelhantes de ausência de marcas de número e reforça o papel da escolaridade sobre o fenômeno.

António (2011) e Bavo (2011) seguem o trabalho de Nhongo (2005), investigando textos produzidos por universitários. Enquanto António destaca frases em que encontrou "desvios" à concordância verbal, Bavo (2011) tem como proposta fundamental apresentar uma listagem de exercícios, a ser usada em sala de aula para o treinamento da concordância verbal, nos casos em que os alunos apresentar maior dificuldade de aplicação das regras do PE. Já Jeque (1996), seguindo outra linha de pensamento, testa a hipótese de que a ausência de pluralidade estaria relacionada ao maior preenchimento de sujeito, mas seus resultados não confirmaram a constatação. Por fim, Moreno; Tuzine (1997) analisaram o papel dos fatores sociais sobre a variação no Português de Moçambique, utilizando o corpus de Gonçalves (1997), e concluem que as variáveis sociais atuam em conjunto sobre os dados e não isoladamente.
Por sua vez, o estudo de Pissurno (2017), de cunho quantitativo, aponta para uma alta produtividade de concordância padrão, com 96,8\% de aplicação das marcas de terceira pessoa do plural, o que sugere a adoção do modelo semicategórico de marcação do PE. Acontece que, ao observar qualitativamente os dados, notouse que a natureza de alguns contextos, linguísticos e extralinguísticos, nos quais as marcas de plural estavam ausentes (verbos de alta saliência fônica, sujeitos animados, estruturas na ordem direta SVO) é semelhante ao que se verifica no PB.

Com o intuito de explorar a possível diferença entre os falantes de Português L1 e L2 em Moçambique, Pissurno (2019), em trabalho apresentado em congresso (ABRALIN 50), investigou apenas alguns falantes de $\mathrm{L} 1$, retirados da amostra de 2017, e identificou 96,7\% de marcação de plural. Nesse breve estudo, constatou-se que somente a escolaridade e a posição do sujeito interferiam sobre a concordância verbal padrão, sendo as únicas variáveis que a desfavoreciam. Dessa forma, confirmou-se que o conhecimento de Língua Portuguesa como materna faz com que os indivíduos produzam estruturas mais semelhantes às encontradas no $\mathrm{PE}$, sua suposta variedade de aquisição.

Sendo assim, as pesquisas brevemente retomadas permitem identificar algumas tendências, ora semelhantes, ora divergentes, entre as variedades de Língua Portuguesa quanto ao fenômeno da concordância verbal. Por sua vez, o presente artigo tem por objetivo possibilitar a observação da situação dos falantes de Português como segunda língua, tendo em vista o processo de formação da variedade moçambicana e a construção de sua identidade linguística. 


\section{Aspectos teóricos e metodológicos}

Partindo do arcabouço teórico da Teoria da Variação e Mudança (WEINREICH; LABOV; HERZOG, 1968), adota-se o pressuposto geral da heterogeneidade ordenada (WEINREICH, LABOV, HERZOG, 1968). De acordo com esse princípio, as formas variantes, de mesmo valor referencial e empregadas no mesmo contexto por indivíduos de uma mesma comunidade de fala, ocorrem em função de restrições linguísticas e extralinguísticas.

Para a realização de uma análise multivariada, a partir do programa estatístico Goldvarb-X, ferramenta utilizada em pesquisas de cunho sociolinguístico para a geração de percentuais e pesos relativos, foram realizadas as seguintes etapas: coleta de dados, codificação de dados segundo variáveis já preestabelecidas, realização de rodadas no programa e interpretação, quantitativa e qualitativa, dos resultados.

Em relação à coleta de dados, o estudo vale-se de 9 entrevistas ${ }^{3}$ da Amostra Maputo, retiradas do Corpus Moçambique-PORT (VIEIRA; PISSURNO, 2016), que integra o Projeto Estudo comparado dos padrões de concordância em variedades africanas, brasileiras e europeias do Português (Projeto ALFAL 21). Trata-se, especificamente, de informantes da área urbana da cidade de Maputo, que se declaram falantes de Português como segunda língua. A distribuição desses indivíduos foi feita de acordo com o sexo do informante (feminino ou masculino), dois níveis de escolaridade (ensino fundamental ou médio) e três faixas etárias (de 18 a 35 anos, de 36 a 55 anos ou acima de 56 anos), como apresenta o quadro 1 , a seguir:

Quadro 1. Distribuição dos informantes falantes de Português L2 na Amostra Maputo

\begin{tabular}{|c|c|c|c|c|}
\hline Escolaridade / Sexo Idade & \multicolumn{2}{|c|}{ Ensino Fundamental } & \multicolumn{2}{c|}{ Ensino Médio } \\
\hline & Homem & Mulher & Homem & Mulher \\
\hline Faixa A (18-35 anos) & A1H & A1M & - & A2M \\
\hline Faixa B (36-55 anos) & B1H & B1M & - & B2M \\
\hline Faixa C (acima de 56) & C1H & - & C2H & C2M \\
\hline
\end{tabular}

Como é possível notar, não há uma distribuição uniforme das células, como é esperado em análises sociolinguísticas clássicas. Ocorre que, devido ao curto tempo obtido para a realização das entrevistas, não foi possível preencher as células de maneira que obtivéssemos 18 indivíduos falantes de Português L1 e/ou somente falantes de L2. Ademais, não foram encontrados falantes de L2 com ensino superior naquele momento. Sendo assim, a amostra utilizada em Pissur- no (2017) mesclava falantes dos dois perfis e, no presente estudo, serão apresentados os

30 critério de escolha desses informantes foi, primeiramente, a separação entre falantes de Português como língua materna ou como segunda língua da amostra geral e, em segundo lugar, o preenchimento das células de acordo com os perfis disponíveis. Na amostra como um todo há 35 informantes, sendo que, desses, apenas 12 se declaram falantes de Português L2 e 3 deles estão em células repetidas, ou seja, correspondem a um mesmo perfil social já contemplado no quadro 1, e, por isso, ficaram de fora desse estudo. 
resultados de alguns indivíduos que também estavam considerados em 2017 e outros que não haviam sido investigados anteriormente, todos falantes de uma língua materna Bantu e que aprenderam o Português posteriormente, seja com a família ou na escola.

É válido salientar que a heterogeneidade da amostra reflete a verdadeira situação moçambicana, uma vez que, devido à influência do multilinguismo encontrado na região, dificilmente serão encontrados falantes com experiências muito semelhantes em relação ao conhecimento do Português e das outras línguas em contato. Dessa forma, todo resultado apresentado sobre essa realidade e dentro do material disponível, ainda que fora dos padrões previstos pela Sociolinguística, deve ser considerado como mais um passo em direção à caracterização dessa variedade.

Para além das variáveis referentes à constituição da amostra (idade, escolaridade e sexo), a pesquisa também observou a atuação de uma outra variável social, língua(s) dominada(s) pelo informante, codificada a partir das declarações dos próprios entrevistados, que informavam quais outras línguas conhecia e se as usava na mesma proporção que o Português, em determinados contextos, ou se as usava mais do que o próprio Português. A hipótese atrelada a essa variável é a de que, quanto maior for o contato com as línguas Bantu, que possuem marcação de plural prefixal e não sufixal como o Português (cf. ARMANDO RIBEIRO, 2009), maiores seriam as chances de não

4 Outro fato a ser destacado é que esses informantes não são todos falantes de mesma língua Bantu materna, pois não houve possibilidade uma estratificação que tratasse apenas falantes da mesma L1. Assim, a título de explicação, suas línguas maternas são: A1H - Cimanyica, B1H e A1M - Emakhuwa, A2M - Cinyungwe, C2H - XiRhonga, C1H, B1M, B2M e C2M - XiChangana. haver concordância padrão na fala desses indivíduos.

Com relação aos condicionamentos estruturais, foram controladas as seguintes variáveis: posição do sujeito em relação ao verbo, distância entre o núcleo do SN e o verbo, presença de elementos intervenientes, configuração morfossintática do sujeito, número de constituintes do sujeito, paralelismo no nível oracional (do sujeito para o verbo), animacidade do referente sujeito, saliência fônica, tempo/modo verbal e transitividade verbal.

A última etapa, por fim, foi a execução das rodadas multivariadas no Goldvarb-X, de acordo com a distribuição de perfis mencionada no quadro 1 , que gerou os números para a análise e selecionou as variáveis relevantes para a amostra, quais sejam, nesta ordem: língua(s) dominada(s) pelo informante, transitividade verbal, escolaridade e animacidade do sujeito. Para a organização do texto, serão apresentadas as variáveis sociais primeiro, seguidas das linguísticas e, logo após, uma breve discussão qualitativa dos dados, que auxiliarão no estabelecimento de um continuum de padrões de concordância verbal das variedades do Português.

\section{Análise quantitativa dos resultados: a concordância verbal no português L2 de moçambique}

Verificou-se, na presente amostra, o comportamento de uma regra variável, no limite extremo de uma semicategórica, consoante Labov (2003), revelando 94,9\% de marcas explícitas de plural nos verbos de terceira pessoa. Assim, dentre os 836 dados coletados, apenas 45 apresentam ausência de concordância padrão, ou seja, somente 5,1\% das ocorrências não possuem pluralidade padrão. 
Tabela 1. Distribuição dos dados com e sem marca verbal de P6 no Português de Moçambique (PM)

\begin{tabular}{|c|c|c|}
\hline & Ocorrências & Percentual \\
\hline Concordância padrão & $836 / 881$ & $94,9 \%$ \\
\hline Concordância não padrão & $45 / 881$ & $5,1 \%$ \\
\hline
\end{tabular}

\section{- Restrições extralinguísticas}

Foram selecionadas duas variáveis extralin(em primeiro lugar) e escolaridade (em terguísticas no tratamento estatístico dos dados: língua(s) dominada(s) pelo informante ceiro lugar). Detalhando a primeira delas, observe-se a Tabela 2, a seguir:

Tabela 2. Atuação da variável língua(s) dominada(s) pelo informante para a não marcação de 3ª pessoa plural no PM.

\begin{tabular}{|c|c|c|c|}
\hline & Ocorrências & Percentual & Peso Relativo \\
\hline $\begin{array}{c}\text { Fala Português e } \\
\text { línguas locais }\end{array}$ & $32 / 833$ & $3,8 \%$ & .46 \\
\hline $\begin{array}{c}\text { Fala mais línguas locais } \\
\text { do que Português }\end{array}$ & $13 / 48$ & $27 \%$ & .90 \\
\hline
\end{tabular}

Como é possível perceber, o maior contato com as línguas locais desfavorece a presença de marcas de número (.90 para não concordância), enquanto os indivíduos que declaram falar Português e língua Bantu em uma frequência mais proporcional, seriam mais sujeitos a favorecer o uso das marcas (.46 para não concordância). Acredita-se que, nesse segundo caso, por serem bilíngues propriamente ditos, os informantes possuem conhecimento similar das línguas envolvidas e, portanto, ainda que possam existir estruturas diferentes para a marcação da concordância verbal em cada idioma, um não interfere com tanta intensidade na produção do outro.

Ressalte-se ainda que o grupo "fala mais línguas locais do que Português" possui apenas um informante, que destoa bastante dos outros oito entrevistados, não só por ser o único que afirma usar mais línguas locais, mas também por apresentar dificuldades com o processamento da concordância de forma geral, tendo produzido ausência de marcas verbais, nominais e até de gênero ao longo da entrevista. Esse indivíduo, sozinho, é responsável por 13 das 45 ocorrências sem marca, ou seja, 27\% de não concordância padrão.

Além disso, uma observação atenta da terceira variável selecionada pelo programa, a escolaridade, revela que, em termos extralinguísticos, não é apenas o domínio e a maior frequência de uso de língua locais que atua sobre o desfavorecimento das marcas de plural. Como a Tabela 3 mostra, os anos de estudo formal também afetam os resultados. Assim, aqueles que possuem apenas o ensino fundamental são mais propensos a oscilar na marcação dos verbos (.72 para não concordância) do que aqueles que possuem ensino médio (.37 para não concordância). 
Uma análise sociolinguística sobre a concordância verbal de terceira pessoa do plural e o contato linguístico no Português L2 da variedade moçambicana

Tabela 3. Atuação da variável escolaridade para a não marcação de 3 a pessoa plural no PM.

\begin{tabular}{|c|c|c|c|}
\hline & Ocorrências & Percentual & Peso Relativo \\
\hline Ensino Fundamental & $31 / 306$ & $10,1 \%$ & .72 \\
\hline Ensino Médio & $14 / 575$ & $2,4 \%$ & .37 \\
\hline
\end{tabular}

Ao que tudo indica, a questão da escolaridade está ligada ao fato de que, para muitos habitantes de Moçambique, especialmente os que falam Português como segunda língua, seu maior contato com a Língua Portuguesa é, de fato, na escola. Consequentemente, supõe-se que os indivíduos que permanecem por mais anos dentro da escola têm a possibilidade de desenvolver mais habilidades na língua e, ao mesmo tempo, adquirir com mais facilidade as suas regras formais.

Esse comportamento escalar dos níveis de escolaridade é muito similar ao que ocorre nas variedades brasileiras, isto é, mais anos de ensino formal favorecem a presença de marcas de número nos verbos. Dessa maneira, essa é uma característica que aproxima o PM do PB, já que, como esclarecem
Vieira; Brandão (2014, p. 95), "em qualquer das amostras do PE, fica nítido que, independentemente do grau de escolaridade, é nítida a opção preferencial pelas marcas de pluralidade", ou seja, no Português Europeu esse aspecto social não parece afetar os resultados.

\section{- Restrições linguísticas}

A segunda variável destacada pelo programa estatístico foi a transitividade verbal. Nesse grupo de fatores, verificou-se que os verbos do tipo inacusativo e copulativo tendem a desfavorecer as marcas de plural em .79 e .77, respectivamente. Por outro lado, os verbos inergativos (.41 para não concordância) e transitivos (.39 para não concordância), favorecem a presença das marcas.

Tabela 4. Atuação da variável transitividade para a não marcação de 3 a pessoa plural no PM.

\begin{tabular}{|c|c|c|c|}
\hline & Ocorrências & Percentual & Peso Relativo \\
\hline Inergativo & $5 / 80$ & $6,2 \%$ & .41 \\
\hline Inacusativo & $10 / 55$ & $18,2 \%$ & .79 \\
\hline Transitivo & $24 / 577$ & $4,2 \%$ & .39 \\
\hline Copulativo & $5 / 166$ & $3 \%$ & .77 \\
\hline
\end{tabular}

Vejam-se os exemplos retirados da amostra:

1. há pessoas que trabalham estão bem posicionados (PMOA1H)

2. mas existe casos em que:... prontos... as mulheres casam e o marido diz "não vai mais à escola" (PMOB2M)

3. os dois fazem os trabalhos de casa o mata-bicho depois vão trabalhar (PMOA2M)

4. os machanganas... sim... era daqueles que por exemplo... (PMOB2M)

Por outro lado, cabe destacar que, ao observar os números da Tabela 4 , há uma quantidade significativa de verbos do tipo transitivo (24) que não apresentam marcas nessa amostra, revelando que, mesmo que estatisticamente não seja relevante, esse é um dado de natureza distinta das hipóteses gerais de verbos que facilitam ou não a presença da concordância.

Por fim, a quarta e última variável indicada estatisticamente foi a animacidade do sujeito, cujos resultados são apresentados 
na Tabela 5. Ao passo que sujeitos animados favorecem a concordância (.44 para não concordância), os inanimados a desfavorecem (.76).

Tabela 5. Atuação da variável animacidade do sujeito para a não marcação de 3 a pessoa plural no PM.

\begin{tabular}{|c|c|c|c|}
\hline & Ocorrências & Percentual & Peso Relativo \\
\hline Sujeito Animado & $33 / 712$ & $4,4 \%$ & .44 \\
\hline Sujeito Inanimado & $12 / 136$ & $8,8 \%$ & .76 \\
\hline
\end{tabular}

A seguir, destacam-se exemplos desse grupo de fatores:

5. eles falam português diferente do nosso (PMOA2M)

6. tem coisas que acontece você encontra miúdo de qualquer maneira a mãe já não quer saber porque a mãe faz o filho deixa com o avô (PMOA1H)

Salienta-se que, da mesma forma que ocorre com os verbos transitivos na variável transitividade, a situação dos sujeitos animados também merece um olhar mais atento. Assim, nota-se a ocorrência de 33 sujeitos com traço animado sem marcas de pluralidade nessa amostra, o que revela outra natureza distinta de dados. Desse modo, essas ocorrências que, hipoteticamente, contrariam as tendências gerais ao serem observadas qualitativamente, serão verificadas a seguir.

\section{- Análise qualitativa dos dados da amostra}

Após a exposição da análise quantitativa dos dados, é válido destacar algumas ocorrências encontradas na amostra que revelam a diferença entre os contextos sem marca verificados nessa variedade e aqueles mais comuns e universais já identificados na variedade europeia (cf. Seção 2).

Antes de apresentar tais exemplos, cabe ressaltar que, dentre os nove informantes analisados, somente um não apresentou quaisquer ocorrências sem concordância padrão - C2M. Essa informante, ainda que falante de Português L2, declara que seus pais sempre exigiram o uso de Português em casa e, além disso, todo seu estudo formal foi realizado em escolas portuguesas, nas quais as línguas locais eram proibidas. Dessa maneira, pode-se supor que a sua intensa frequência de uso da Língua Portuguesa, atrelada ao menor uso de línguas locais, tenha influência sobre sua preferência pelas marcas padrão.

Os outros oito indivíduos, por sua vez, produziram estruturas com e sem marcas de plural ao longo das entrevistas. Observem-se, então, alguns destaques em que a marca de número foi omitida:

7. há zonas que eles mais preferem ficar assistir... no quarto assistir um filme há zonas que gosta mais de ficar a fumar (PMOA1H)

8. conflitos armados e:: guerra que assola lá na zona centro (PMOB1H)

9. era até dias quente ((risos)) era dias quente (PMOB2M)

10. falam-se mais nessa língua porque nem todas pessoas conseguiu falar português (PMOA1H)

11. porque eu sou pobre eles também consegue ver que há de sair com coisas (PMOB1M)

12. mas hoje eu vejo até algumas famílias fazer pressão (PMOC2H) 
13. para nossas criança elas que vai fazer furo / futuro melhore... (PMOC1H)

14. da mesma forma que minhas mãe/o me/ os meus pais me criou (PMOA1M)

15. são as crianças nasceu na minha vida (PMOC1H)

16. seus pais é velho tudo lá a pedir esmola (PMOC1H)

Os exemplos (7) e (8) representam a atuação do pronome relativo sobre a ausência de marca nos verbos "gosta" e "assola", contexto que costuma facilitar a não concordância. A ocorrência (9) também demonstra outra tendência universal para a falta de concordância padrão - a posposição do sujeito. No entanto, como se pode notar nos dados (10), (11) e (12), foram encontrados verbos sem pluralidade mesmo em estruturas na ordem direta. Assim, ainda que os sujeitos dessas orações estejam antepostos (todas pessoas, eles, algumas famílias), os verbos não receberam marcas de plural.

0 efeito da saliência fônica, fator não considerado como significativo nessa amostra, mas que é válido de nota, aparece sobre os dados de (11) a (16), mostrando que ocorrem verbos sem marca de número em todos os níveis de diferenciação fônica e não somente nos mais baixos. Dessa maneira, há verbos sem plural nos graus 1 (consegueconseguem), 2 (fazer-fazerem), 3 (vai-vão), 4 (criou-criaram, nasceu-nasceram) e até mesmo no 5 (é-são), o que infirma a hipótese geral, nesses dados, de que os níveis mais altos de saliência facilitam a concordância.

Outro fator digno de observação é que a maioria dos exemplos destacados possui sujeitos de traço animado (10) ao (16), o que negaria mais uma tendência universal de não marcação nessa amostra. Além disso, também é possível perceber que os verbos destacados não são somente do tipo copulativo, inergativo ou inacusativo, que já carregam uma tendência à ausência de marcas. Desse modo, há verbos transitivos sem pluralidade, como em (7), (10), (11), (12), (13) e (14).

Essa breve exemplificação das ocorrências retiradas da amostra permite a reflexão de que a natureza dos dados sem marcas de plural não tem o mesmo perfil do que é encontrado na variedade europeia do Português. Em outras palavras, apesar de a variedade moçambicana apresentar altos índices de preferência pela concordância, similarmente ao PE, a análise qualitativa dos dados indica que, ao lado dos contextos considerados mais universais, que facilitam a ausência de marcas (presença de pronome relativo, verbos inacusativos e copulativos, posposição do sujeito, traços inanimados do sujeito, baixa saliência fônica), há ocorrências sem plural em estruturas não encontradas no PE, mas que são recorrentes também na variedade brasileira: sujeitos antepostos e animados, alta saliência fônica, verbos transitivos, além da atuação da escolaridade, fator social que não é relevante em variedades europeias, como já foi mencionado.

Considerando tal cenário, Pissurno (2017), à luz do continnum afro-brasileiro de Petter (2015), propõe que as variedades de Língua Portuguesa sejam distribuídas dentro de um continnum de padrões de concordância, de forma a localizar o Português de Moçambique em relação ao Português Brasileiro e ao Europeu. Seguindo a mesma linha de raciocínio para incluir o presente trabalho no continuum, a representação seria a seguinte: 
Figura 1. Continuum de variedades do Português: padrões de concordância

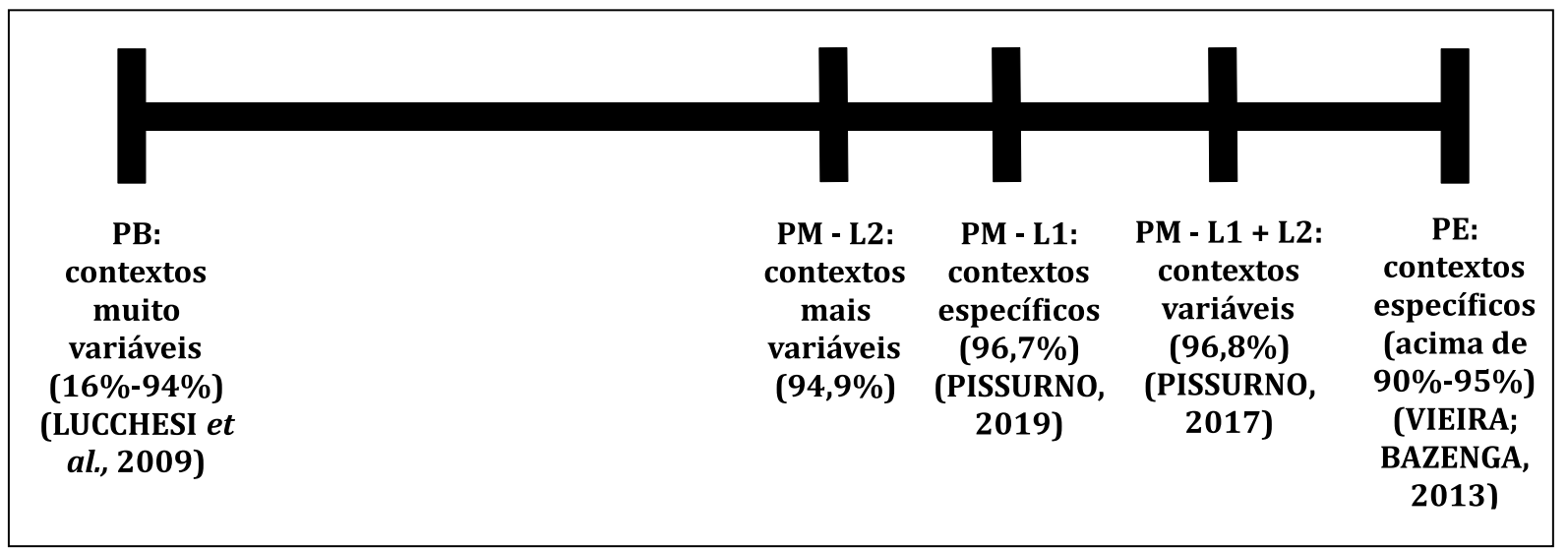

Fonte: Adaptado de Pissurno (2017)

As variedades brasileira e europeia assumiriam os extremos do continuum, por apresentarem comportamentos muito opostos, ou seja, enquanto o PB possui índices bastante variados de marcação (16\% a 94\%, de acordo com Lucchesi et al. (2009) e inúmeros contextos com ausência de marca de número, o PE indica níveis altíssimos de preferência pelas marcas padrão (acima de 95\%) e, quando há registros de ausência das mesmas (de 90\% a 94\%), essas ocorrem em contextos muito específicos, considerados universais, para o desfavorecimento da concordância de P6, como a posposição do sujeito, por exemplo (cf. VIEIRA; BAZENGA, 2013).

Já os trabalhos realizados sobre a variedade moçambicana revelam um comportamento instável dos dados, uma vez que os percentuais, em geral, são semelhantes aos do $\mathrm{PE}$, mas a análise qualitativa dos dados indica contextos de não marcação de diferentes naturezas:

(i) em Pissurno (2017), o trabalho que mescla falantes tanto de Português língua materna quanto segunda língua apontou para uma regra semicategórica $(96,8 \%$ de aplicação da regra), apresentando contextos de ausência de concordância muito variáveis (ordem SVO, alta saliência fônica, sujeitos animados e antepostos, verbos transitivos); (ii) em Pissurno (2019), o estudo apresentado na ABRALIN 50, que observava apenas os falantes de Português língua materna, também mostrou um comportamento semicategórico (96,7\%). Contudo, apenas as variáveis escolaridade (relevante apenas nas variedades brasileiras) e posição do sujeito (de caráter universal) foram selecionadas estatisticamente;

(iii) na presente análise, que considerou apenas falantes de Português como segunda língua, obteve-se 94,9\% de aplicação das regras de concordância, um comportamento no limite entre a regra variável e a semicategórica (LABOV, 2003), indicando que, qualitativamente, os dados sem marca são encontrados em estruturas variadas, diferentes daquelas consideradas como universalmente facilitadoras da ausência de marcas de número.

Dessa forma, os estudos da Amostra Maputo tomam posições intermediárias dentro do continuum proposto, já que, quantitativamente, estariam mais próximos da variedade europeia, mas, qualitativamente demonstram variação em contextos mais similares aos verificados na brasileira. É essa oscilação, entre um comportamento mais ou menos variável, que ratifica a hipótese de que a variedade moçambicana estaria ainda em processo de formação, como explica Pissurno (2017): 
Essa constatação reflete, em uma proposta de estabelecimento de um continuum de padrões de concordância e à luz do continuum afro-brasileiro, a posição do PM no meio do caminho, isto é, apesar de apresentar um nível bastante alto de preferência pela concordância padrão, seguindo seu modelo Europeu de (possível) aquisição, ele se afastaria do PE e se aproximaria mais das variedades parcialmente reestruturadas, como a brasileira, por exibir contextos mais variáveis de não aplicação da regra.

Considerando que há forte influência de línguas locais no Português falado em Moçambique, para além de todas as formas de acesso à Língua Portuguesa, a variedade em questão pode ser analisada como ainda em processo de formação, construindo sua identidade linguística, a partir dos meios plurais de aquisição de língua aos quais é exposta. (PISSURNO, 2017, p. 199)

A autora ainda comenta que há três aspectos relevantes que podem influenciar a formação da variedade moçambicana quanto aos padrões de concordância verbal:

(i) o modelo supostamente padrão do Português Europeu - com marcação (semi-) categórica de pluralidade - ao qual teriam certo (provável) acesso na escola; (ii) a semelhança com o modelo brasileiro - com marcação variável de pluralidade - na sua constituição, especialmente por causa do contato multilinguístico e de sua tendência geral de simplificação morfológica; e (iii) os parâmetros das línguas locais (marcas de número sempre prefixais, ao contrário do padrão sufixal do Português), que, para muitos dos habitantes de Moçambique, são suas línguas maternas e com as quais convivem diariamente. (PISSURNO, 2017, p. 199-200)

Sendo assim, pode-se conjecturar que o índice observado no presente estudo revela que ser falante de Português como segunda língua possibilita, de fato, um comportamento mais variável. Em outras palavras, pode-se dizer que os contextos mais variá- veis nos quais não houve concordância foram encontrados em maior quantidade nos dados de falantes de Português L2, em comparação com o estudo que observou apenas falantes de L1.

Portanto, pressupõe-se que o contato com as línguas locais pode mesmo alterar, em certa medida, as estruturas da Língua Portuguesa falada por esses indivíduos e que, por ser uma variedade ainda recente (cerca de 45 anos como língua oficial do país), suas características não estejam totalmente definidas, revelando comportamento oscilante, ora semelhante ao PB, ora ao PE, sem contar que pode possui traços específicos, devido ao forte contato multilinguístico que é atual e não ocorre nas outras duas variedades.

\section{Considerações finais}

Após toda a discussão apresentada, pode-se confirmar que os objetivos traçados para o trabalho foram alcançados, isto é, descreveram-se os dados de fala de informantes de Português L2, identificaram-se as características sociais e linguísticas que favorecem a ausência de marcas de número nos verbos e apontou-se a localização do Português de Moçambique no continuum de variedades do Português, quanto ao fenômeno da concordância verbal. Em relação às hipóteses levantadas para o estudo, retomam-se as perguntas iniciais apresentadas na introdução, para que sejam traçadas as suas conclusões:

(i) qual é a influência do Português como L2 sobre os resultados alcançados?

Os resultados indicam que os falantes de Português como L2 demonstram comportamento de uma regra variável (94,9\%), embora no limite estabelecido por Labov (2003), quanto aos padrões de concordân- 
cia verbal, diferentemente dos falantes de L1 que apresentam regra semicategórica de marcação $(96,7 \%)$, confirmando a hipótese de que há estruturas diferentes quando o Português é L1 ou L2 dos indivíduos;

(ii) quais variáveis se mostram influentes no cancelamento das marcas de número?

O programa estatístico selecionou como relevantes quatro variáveis, quais sejam, língua(s) dominada(s) pelo informante, escolaridade, tipo de verbo e animacidade, evidenciando as seguintes tendências: falantes que usam mais línguas locais e com menos anos de escolaridade; verbos do tipo inacusativo e copulativo e sujeitos inanimados favorecem a ausência de marcas de plural. Assim, houve um balanço entre as variáveis sociais e linguísticas, o que não confirma nem infirma a hipótese geral de que as sociais seriam mais relevantes, já que, como foi observado, ser falante de L2 é fator significativo, e socialmente motivado, para a variação das marcas;

(iii)o Português de Moçambique já pode ser considerado uma variedade nativizada ou ainda é uma variedade em formação?

Observou-se um comportamento instável nos dados da amostra, apontando características quantitativas semelhantes ao PE (perfil mais semicategórico) e qualitativas mais semelhantes ao PB (contextos mais variáveis de não marcação: escolaridade, sujeitos antepostos e animados, saliência em graus altos) o que indica, como a hipótese previa, um quadro de variedade em formação.

Em resumo, conclui-se que o Português de Moçambique tenha ainda muitas características a serem descobertas, mas espera-se que o presente trabalho tenha contribuído, ainda que de forma preliminar, para a criação de hipóteses relacionadas à formação da variedade moçambicana, auxiliando não só as reflexões sobre como o contato multilinguístico pode influenciar os padrões gramaticais de uma dada língua, mas também demonstrando como o PM se comporta no cenário de variedades da Língua Portuguesa, em uma espécie de continuum dos padrões de concordância.

\section{Referências}

ANTÓNIO, Tuaha. Estratégias de ensino da concordância verbal em número à população universitária moçambicana. 76f. Dissertação (Mestrado em Língua Portuguesa). Maputo: Faculdade de Letras/UEM, 2011.

ARMANDO RIBEIRO, C. M. Dicionário gramatical Changana. Moçambique: Paulinas, 2009.

BAVO, Názia. Prática de estruturas: Concordância verbal em número. 2011. Disponível em: www.catedraportugues.uem.mz/lib/docs/N.Bavo_fINAL20Abril2012.pdf. Acesso em: 17 de dezembro de 2015.

BRANDÃO, Silvia F; VIEIRA, Silvia R. A concordância verbal e nominal no português do Brasil e no português de São Tomé: uma abordagem sociolinguística. Papia, São Paulo, v. 22, n. 1, p. 7-40, 2012a.

Concordância nominal e verbal: contribuições para o debate sobre o estatuto da variação em três variedades urbanas do português. Alfa, São Paulo, v. 56, n. 3, p. 1035-1064, 2012b.

DIAS, Hilzidina N. Diversidade cultural e educação em Moçambique. In: Revista V!RUS, São Carlos, n. 4, dez. 2010. Disponível em: <http:// www.nomads.usp.br/virus/virus04/?sec=4\&item $=4$ \&lang=pt $>$. Acesso em: 10 de dezembro de 2019.

FIGUEIREDO, Carlos F. G. A concordância variável no sintagma nominal plural do Português restruturado de Almoxarife (São Tomé). Revista de Crioulos de Base Lexical Portuguesa e Espanhola, Lisboa, v. 1, n. 1, p. 28-55, 2009.

GANDRA, Ana S. A concordância verbal no português europeu rural. In: OLIVEIRA, Klebson.; CUNHA, Hirão F.; GOMES, Luis (Orgs.). Novos tons de Rosa... para Rosa Virgínia Mattos e 
Uma análise sociolinguística sobre a concordância verbal de terceira pessoa do plural e o contato linguístico no Português L2 da variedade moçambicana

Silva. Salvador: EDUFBA, 2009, p. 142-161.

GONÇALVES, Perpétua. Tipologia de erros do Português Oral de Maputo: um primeiro diagnóstico. In: GONÇALVES, P.; STROUD, C. (Orgs.) Panorama do Português oral de Maputo, v. II - A construção de um Banco de "Erros". INDE - Cadernos de Pesquisa no 24. Maputo: Moçambique, 1997, p. 35-67.

; STROUD, C. (Orgs.) Panorama do Português oral de Maputo, v. III - Estruturas Gramaticais do Português: Problemas e Exercícios. INDE - Cadernos de Pesquisa no 27. Maputo, Moçambique, 1998.

; A gênese do Português de Moçambique. Lisboa: INCM, 2010.

; CHIMBUTANE, Feliciano S. (Org.) Multilinguismo e Multiculturalismo em Moçambique: Em direção a uma coerência entre discurso e prática. Moçambique. Alcance Editores, 2015.

GRACIOSA, Diva. Concordância verbal na fala culta carioca. Dissertação (Mestrado em Língua Portuguesa). Rio de Janeiro: Faculdade de Letras/UFRJ, 1991.

Instituto Nacional de Estatística, IV Recenseamento Geral da População e Habitação - 2017: Indicadores Sócio-Demográficos, Moçambique, Maputo, Instituto Nacional de Estatística (INE). 2017.

JEQUE, Avelino. 0 enfraquecimento da morfologia flexional verbal (pessoa e número) no português de Moçambique. 80f. Dissertação (Licenciatura em Língua Portuguesa). Maputo: Faculdade de Letras/UEM, 1996.

JON-AND, Anna. Variação, contato e mudança linguística em Moçambique e Cabo Verde. A concordância variável de número em sintagmas nominais do português. Tese (Doutorado). Suécia: Stockholm University, 2011.

JUSTINO, Victor. Concordância verbal em número: da descrição linguística à avaliação no contexto de ensino-aprendizagem. In: BASTOS, Mónica; MARQUES, José; MONTEIRO, Ana; SIOPA, Conceição. (Orgs). Ensinar a língua portuguesa em Moçambique: Desafios, possibilidades e constrangimentos. Textos selecionados das VII Jornadas da Língua Portuguesa, p. 166-186. Porto: Porto Editora, 2015.
LABOV, William. Some sociolinguistic principles. In: PAULSTON, Christina B.; TUCKER, Richard G. (Org.). Sociolinguistics: the essential readings. Oxford: Blackwell, 2003, p. 235-250.

LUCCHESI, Dante; BAXTER, Alan; RIBEIRO, Ilza (orgs.). 0 português afro-brasileiro. Salvador: EDUFBA, 2009

; SILVA; Jorge Augusto A. A concordância verbal. In: LUCCHESI, Dante, BAXTER, Alan; RIBEIRO, Ilza. (Orgs.). 0 português afro-brasileiro. Salvador: EDUFBA, 2009.

MONGUILHOTT, Isabel O. S. Estudo sincrônico e diacrônico da concordância verbal de $3^{\text {a }}$ pessoa do plural no PB e no PE. 229f. Tese (Doutorado em Linguística e Língua Portuguesa). Florianópolis: Faculdade de Letras/UFSC, 2009.

MONTE, Alexandre. Concordância verbal e variação: um estudo descritivo-comparativo do Português Brasileiro e do Português Europeu. 171f. Tese (Doutorado em Linguística e Língua Portuguesa). São José do Rio Preto: Faculdade de Letras/UNESP, 2012.

MORENO, Albertina; TUZINE, António. Distribuição social de variáveis linguísticas no Português Oral de Maputo. In: GONÇALVES, Perpétua.; STROUD, Christopher. (Orgs.) Panorama do Português oral de Maputo. Volume II - A construção de um Banco de "Erros". INDE Cadernos de Pesquisa no 24. Maputo: Moçambique, 1997, p.71-91.

NARO, Anthony J. The social and structural dimensions of a syntatic change. Language. v. 57, p. 35-69, 1981.

NHONGO, Názia. A concordância verbal em número no discurso escrito de estudantes universitários moçambicanos. 90f. Dissertação (Licenciatura em Língua Portuguesa). Maputo: Faculdade de Letras/UEM, 2005.

PETTER, Margarida M. Ampliando a investigação do continuum afro-brasileiro de Português. Papia, São Paulo, v. 2, n. 25, p. 305-317, 2015.

PISSURNO, Karen C. S. A concordância verbal de terceira pessoa do plural na variedade moçambicana do Português: uma abordagem sociolinguística. 222f. Dissertação (Mestrado em Língua Portuguesa). Rio de Janeiro: Faculdade de Letras/UFRJ. 2017. 
PISSURNO, Karen C. S. A influência do contato linguístico na concordância verbal de terceira pessoa no Português Moçambicano. Trabalho apresentado no Congresso Abralin 50. Maceió, 2019.

RUBIO, Cássio F. Padrões de concordância verbal e de alternância pronominal no português brasileiro e europeu: estudo sociolinguístico comparativo. 391f. Tese (Doutorado em Estudos Linguísticos). Instituto de Biociências, Letras e Ciências Exatas, Universidade Estadual Paulista "Júlio Mesquita Filho". UNESP, São José do Rio Preto, 2012.

SCHERRE, Marta M. P; NARO, Anthony J. Mudança sem mudança: a concordância de número no português brasileiro. Sripta, Belo Horizonte, v. 9, n. 18, p. 109-131, 2006.

SITOE, Bento; NGUNGA, Armindo. Relatório do II Seminário sobre a Padronização da Ortografia de Línguas Moçambicanas, NELIMO - Centro de Estudos das Línguas Moçambicanas, Universidade Eduardo Mondlane, Maputo, 2000.

VAREJÃO, Filomena. Variação em estruturas de concordância verbal e em estratégias de relativização no português europeu popular. Tese (Doutorado em Língua Portuguesa). Rio de Janeiro: Faculdade de Letras/UFRJ. 2006.

VIEIRA, Silvia R. Concordância verbal: variação em dialetos populares do Norte fluminense. Dissertação (Mestrado em Língua Por- tuguesa). Rio de Janeiro: Faculdade de Letras/ UFRJ, 1995.

. 0 estatuto da regra variável e o fenômeno da concordância verbal em variedades do português. In: CESTERO et. al. (org). Documentos para el XVI Congreso Internacional de la ALFAL. Alcalá de Henares/Espanha: ALFAL/ Universidad de Alcalá, 2011. CDROM.

; BAZENGA, Aline M. A concordância de terceira pessoa plural: padrões em variedades do Português. In: VIEIRA, Silvia R. (Org.) (2015). A concordância verbal em variedades do Português. Rio de Janeiro: Vermelho Marinho, 2013, p. 29-75.

; BRANDÃO, Silvia F. Tipologia de regras linguísticas e estatuto das variedades/línguas: a concordância em português. In: Revista Linguística, Rio de Janeiro, v. 30, n. 2, p. 81-112, 2014.

; PISSURNO, Karen Cristina da Silva (Orgs.). Corpus Moçambique-PORT (2016). Rio de Janeiro: Faculdade de Letras/UFRJ. Disponível em: <www.corporaport.letras.ufrj.br.> Acesso em: 01 de dezembro de 2019.

WEINREICH, Uriel; LABOV, William; HERZOG, Marvin. Empirical foundations for theory of linguistic change. In: LEHMANN, Winfred.; MALKIEL, Yakov. (Eds.) Directions for Historical Linguistics, p. 97-195. Austin: University of Texas Press, 1968.

Recebido em: 13/02/2020 Aceito em: 13/05/2020 